\title{
Levofloxacin-induced rhabdomyolysis: a case report
}

\author{
Febin John ${ }^{1 *}$ (D), Ruby Oluronbi ${ }^{2}$ and C. S. Pitchumoni ${ }^{1}$
}

\begin{abstract}
Background: Rhabdomyolysis secondary to quinolones is not frequent. There are scarce reports in the literature associating rhabdomyolysis to levofloxacin. We describe a case of levofloxacin-induced rhabdomyolysis.

Case presentation: A 52-year-old African-American man presented with muscle tightness after taking three doses of levofloxacin. He had elevated creatine kinase without acute kidney injury. His symptoms resolved after discontinuation of levofloxacin and supportive care.

Conclusions: It is fascinating that our patient has a prior history of rhabdomyolysis, likely from levofloxacin. Our case highlights the need to be mindful of this potentially life-threatening complication of levofloxacin.
\end{abstract}

Keywords: Rhabdomyolysis, Levofloxacin, Drug-induced rhabdomyolysis, Case report

\section{Background}

Levofloxacin is a deoxyribonucleic acid (DNA) gyrase inhibitor that inhibits the relaxation of supercoiled DNA, thus promoting DNA strand breakage. Well-known adverse reactions of levofloxacin are gastrointestinal (nausea and vomiting approximately $5 \%$ ), central nervous system (CNS; seizure $<1 \%$ ), cardiovascular (arrhythmia $<1 \%$ ), and musculoskeletal (tendinitis $<1 \%$ ) [1]. We describe a less-known side effect of levofloxacin, which is a commonly prescribed antibiotic in the United States of America (USA) [2].

\section{Case presentation}

A 52-year-old African-American man with beta thalassemia, gout, and hypertension presented with the chief complaint of tightness and fatigue in his thigh muscles for 2 days that subsequently involved his shoulders and arms causing difficulty with ambulation. He did not have any prodromal or provoking events except that he took three doses of levofloxacin $750 \mathrm{mg}$ prescribed for a lower respiratory tract infection prior to the onset of his symptoms. By the third dose, along with the worsening of symptoms he noticed discoloration of urine. He had a history of rhabdomyolysis 4 years earlier thought to be secondary to levofloxacin. His vital signs were normal

\footnotetext{
*Correspondence: johnfebin35@gmail.com

1 Department of Internal Medicine, Saint Peters University Hospital,

Rutgers-RWJ Medical School, New Brunswick, NJ, USA

Full list of author information is available at the end of the article
}

and a physical examination was significant for generalized muscle tenderness. His urine was dark brown and turbid, and negative for glucose, bilirubin, ketones, leukoesterase, and nitrite but with $4+$ blood and 0 to 2 red blood cells per highpower field. Other laboratory results during the current episode along with a comparison to the prior episode are summarized in Table 1.

Levofloxacin was discontinued and aggressive intravenous hydration was started. His creatine kinase (CK) gradually dropped over the next 10 days to $<5000 \mathrm{U} / \mathrm{L}$. His serum creatinine remained $<1 \mathrm{mg} / \mathrm{dL}$. His aspartate aminotransferase (AST) peaked at $1298 \mathrm{U} / \mathrm{L}$ while alanine aminotransferase (ALT) remained around $300 \mathrm{U} / \mathrm{L}$ and both tapered to a normal level. His clinical improvement correlated with the drop in CK.

\section{Discussion}

Rhabdomyolysis is a severe form of necrotizing myopathy that occurs after acute muscle insult. Drug-induced rhabdomyolysis is well documented and can occur via primary or secondary myotoxic effect. Imbalance between production and utilization of adenosine triphosphate (ATP) in the muscle caused by drugs can lead to direct toxic effect on the sarcolemma. Secondary myotoxicity can occur via CNS depression causing prolonged immobilization and pressure on large muscles [3]. Common causes of rhabdomyolysis such as trauma, exertion, or seizure were absent in this case. Hypophosphatemia, 
Table 1 Comparison of laboratory values during two episodes of rhabdomyolysis

\begin{tabular}{|c|c|c|c|}
\hline Laboratory test & 2015 & 2011 & Normal range \\
\hline White blood cell count & 11.9 & 7.3 & 4.0-11.0 cells per $\mu \mathrm{L}$ \\
\hline Hemoglobin & 11.1 & 9.7 & $13.0-17.0 \mathrm{~g} / \mathrm{dL}$ \\
\hline Hematocrit & 33.3 & 29.8 & $40.0-56.0 \%$ \\
\hline Mean corpuscular volume & 60.6 & 66.6 & $80.0-100.0 \mathrm{fL}$ \\
\hline Red cell count & 5.49 & 4.47 & $4.40-6.20106 / \mathrm{mm}^{3}$ \\
\hline Red cell distribution width & 22.5 & 23.3 & $11.0-16.0 \%$ \\
\hline Blood urea nitrogen & 18 & 17 & $6-20 \mathrm{mg} / \mathrm{dL}$ \\
\hline Serum creatinine & 0.95 & 0.77 & $0.66-1.25 \mathrm{mg} / \mathrm{dL}$ \\
\hline Serum sodium & 136 & 138 & $136-145 \mathrm{mmol} / \mathrm{L}$ \\
\hline Serum potassium & 4.2 & 4.2 & 3.5-5.1 mmol/L \\
\hline Serum phosphorus & 3.6 & 3.3 & $2.7-4.5 \mathrm{mg} / \mathrm{dL}$ \\
\hline Thyroid-stimulating hormone & 3.4 & 2.72 & 0.465-4.68 $\mu \mathrm{lU} / \mathrm{mL}$ \\
\hline Aspartate aminotransferase (AST) & 445 & 1137 & $17-59 \mathrm{U} / \mathrm{L}$ \\
\hline Alanine aminotransferase (ALT) & 133 & 314 & $21-72 \mathrm{U} / \mathrm{L}$ \\
\hline Alkaline phosphatase (ALP) & 50 & 78 & $56-119 \mathrm{U} / \mathrm{L}$ \\
\hline Creatine kinase (CK) & 92,950 & 268,666 & $55-170 \mathrm{U} / \mathrm{L}$ \\
\hline Creatine kinase MB fraction & 9.2 & 6.4 & $0.6-6.3 \mathrm{ng} / \mathrm{mL}$ \\
\hline Lactate dehydrogenase & 5542 & 21500 & $140-271 \mathrm{U} / \mathrm{L}$ \\
\hline Mycoplasma pneumoniae antibody IGM & Negative & - & \\
\hline Influenza $A$ and $B$ rapid antigen & Negative & Negative & \\
\hline
\end{tabular}

IgM, Immunoglobulin $\mathrm{M}$; Cells per $\mu \mathrm{L}$, cells per micro liter; $\mathrm{g} / \mathrm{dL}$, gram per deci liter; $\mathrm{fL}$, femto liter; $10^{6} / \mathrm{mm} 3,10^{6}$ per cubic millimeter; mmol/L, millimol per liter; $\mu \mathrm{IU} / \mathrm{mL}$, micro international units per milliliter; $\mathrm{U} / \mathrm{L}$, units per liter; $\mathrm{ng} / \mathrm{mL}$, nano gram per milliliter

hypokalemia, hypothyroidism, and infections (influenza, mycoplasma) were excluded in our patient. His medications were reviewed and none of them were known to have this adverse reaction [4]. The fact that he recovered after discontinuation of the drug implies the contributory role of levofloxacin.

The earliest report of quinolone-induced rhabdomyolysis was observed by Blain et al. in 1996 [1]. Levofloxacin-induced rhabdomyolysis was first reported in 2000 and thus far only a few cases have been reported [4-7]. Previous reports that rhabdomyolysis occurs within 6 days of initiation of levofloxacin remained true in our case also. The exact mechanism by which levofloxacin induces rhabdomyolysis is not known yet. A theory of vascular hyperpermeability is hypothesized. Localized edema and mononuclear cells in muscles of animal models after a systemic dose of fluoroquinolones support this hypothesis. Tumor necrosis factor $\alpha$ (TNF $\alpha$ ), interleukin 1 (IL-1), histamine, and plasma fibronectin are some of the mediators involved in this vascular hyperpermeability [4]. Levofloxacin can also lead to seizure activity and muscle breakdown by lowering the seizure threshold; however, there was no seizure activity in our patient.

Liver enzyme elevation, as seen in our patient, is common in rhabdomyolysis. ALT, a cytosolic enzyme is found mostly in the liver. On the other hand, AST, which exists in two isoforms (cytosolic and mitochondrial), is found in the liver, heart, skeletal muscles, kidney, brain, and pancreas. Elevated AST is seen in approximately $93 \%$ of cases and the normalization parallels the fall in CK levels [8]. However, only $75 \%$ of cases of rhabdomyolysis have ALT elevations and its fall does not correlate with CK level. Elevations of liver enzymes in rhabdomyolysis may not be indicative of liver injury [8].

Diagnosis of rhabdomyolysis is by elevations in CK in the blood. Although myoglobinuria can occur in $57 \%$ of patients, it often resolves before the rise in CK. Hence, the absence of myoglobinuria does not rule out the diagnosis [3, 4]. Management is by stopping the offending agent along with adequate hydration to prevent acute renal failure. Systemic steroids although reported to have a beneficial effect, were not used in this case due to lack of scientific evidence [7].

\section{Conclusions}

Our case is fascinating given the prior history of rhabdomyolysis establishing a cause-effect relationship of levofloxacin in the etiology of rhabdomyolysis. Thus it is important to be aware and suspect this infrequent but fatal side effect of this commonly prescribed antibiotic. 


\section{Abbreviations}

ALT, alanine aminotransferase; AST, aspartate aminotransferase; ATP, adenosine triphosphate; CK, creatine kinase; CNS, central nervous system; IL-1, interleukin 1; TNFa, tumor necrosis factor a

\section{Acknowledgements}

None.

\section{Funding}

Our case report did not receive any funding for the conduct and preparation of manuscript.

\section{Availability of data and materials}

Consent was obtained from the patient.

\section{Authors' contributions}

FJ and RO prepared the manuscript. CSP reviewed the article. All authors read and approved the final manuscript.

\section{Competing interests}

The authors declare that they have no competing interests.

\section{Consent for publication}

Written informed consent was obtained from the patient for publication of this case report.

\section{Author details}

'Department of Internal Medicine, Saint Peters University Hospital, Rutgers-RWJ Medical School, New Brunswick, NJ, USA. ${ }^{2}$ Department of Internal Medicine, Drexel University College of Medicine, Philadelphia, PA, USA.

\section{Received: 13 February 2016 Accepted: 11 July 2016}

Published online: 24 August 2016

\section{References}

1. Baril L, Maisonobe T, Jasson-Molinier M, Haroche J, Bricaire F, Caumes E. Acute rhabdomyolysis during treatment with ofloxacin - a case report. Clin Infect Dis. 1999;29(6):1598-9.

2. Linder JA, Huang ES, Steinman MA, Gonzales R, Stafford RS. Fluoroquinolone prescribing in the United States: 1995 to 2002. Am J Med. 2005;118(3):259-68.

3. Curry SC, Chang D, Connor D. Drug- and toxin-induced rhabdomyolysis. Ann Emerg Med. 1989;18(10):1068-84.

4. Gupta A, Guron N, Harris M, Bell R. Levofloxacin-induced rhabdomyolysis in a hemodialysis patient. Hemodial Int. 2012;16(1):101-3.

5. Korzets A, Gafter U, Dicker D, Herman M, Ori Y. Levofloxacin and rhabdomyolysis in a renal transplant patient. Nephrol Dial Transplant. 2006;21(11):3304-5.

6. Petitjeans F, Nadaud J, Perez JP, Debien B, Olive F, Villevieille T, et al. A case of rhabdomyolysis with fatal outcome after a treatment with levofloxacin. Eur J Clin Pharmacol. 2003;59(10):779-80.

7. Hirohisa Nakamae MH, Yamane T, Ohta K, Yasutaka Aoyama TK, Sannomiya Y, Tatsumi N. A Case of Rhabdomyolysis due to Levofloxacin. Clin Drug Investig. 2000;20(3):203-5.

8. Weibrecht K, Dayno M, Darling C, Bird SB. Liver aminotransferases are elevated with rhabdomyolysis in the absence of significant liver injury J Med Toxicol. 2010;6(3):294-300.

\section{Submit your next manuscript to BioMed Central} and we will help you at every step:

- We accept pre-submission inquiries

- Our selector tool helps you to find the most relevant journal

- We provide round the clock customer support

- Convenient online submission

- Thorough peer review

- Inclusion in PubMed and all major indexing services

- Maximum visibility for your research

Submit your manuscript at www.biomedcentral.com/submit
Biomed Central 